\title{
Partial oxidation of methanol over highly dispersed vanadia supported on silica SBA-15
}

\author{
C. Hess ${ }^{\mathrm{a}, \mathrm{d}, *}$, Ian J. Drake ${ }^{\mathrm{c}}$, James D. Hoefelmeyer ${ }^{\mathrm{a}}$, T. Don Tilley ${ }^{\mathrm{a}, \mathrm{b}}$, and Alex T. Bell ${ }^{\mathrm{a}, \mathrm{c}}$ \\ ${ }^{a}$ Chemical and Materials Sciences Division, Lawrence Berkeley National Laboratory, Berkeley, CA, 94720, USA \\ ${ }^{\mathrm{b}}$ Department of Chemistry, University of California, Berkeley, CA, 94720, USA \\ ${ }^{\mathrm{c}}$ Department of Chemical Engineering, University of California, Berkeley, CA, 94720, USA \\ ${ }^{\mathrm{d}}$ Present address: Department of Inorganic Chemistry, Fritz Haber Institute of the Max Planck Society, Faradayweg 4-6, 14195, Berlin, Germany
}

Received 12 May 2005; accepted 6 August 2005

\begin{abstract}
The partial oxidation of methanol to formaldehyde (FA) was studied over highly dispersed vanadia supported on mesoporous silica SBA-15 ( $\left.\mathrm{VO}_{x} / \mathrm{SBA}-15\right)$. $\mathrm{VO}_{x} / \mathrm{SBA}-15$ catalysts were prepared by a novel grafting/ion-exchange method and characterized using UV-VIS- and Raman spectroscopy. The resulting surface vanadium oxide species $\left(0-2.3 \mathrm{~V} / \mathrm{nm}^{2}\right)$, grafted on the inner pores of the SBA-15 silica matrix, consist of tetrahedrally coordinated monomeric and polymeric vanadia. $\mathrm{Th}^{\mathrm{VO}} \mathrm{VO}_{x} / \mathrm{SBA}-15$ catalysts are active and highly selective for the production of FA between 300 and $400{ }^{\circ} \mathrm{C}$. Comparison of the reactivity results with literature data reveals that a better catalytic performance can be obtained over vanadia supported on mesoporous silica in comparison with conventional silica samples with the same vanadium loading. Raman characterization of the catalyst after reaction at high conversion indicates that dispersed vanadia partly agglomerates into vanadia crystallites during methanol oxidation.
\end{abstract}

KEY WORDS: supported vanadium oxide; vanadia; SBA-15; methanol oxidation; spectroscopy; Raman.

\section{Introduction}

Mesoporous SBA-15 silica is a promising new support material for catalysts. First, its large internal surface area $\left(>800 \mathrm{~m}^{2} / \mathrm{g}\right)$ and $\mathrm{OH}$ concentration allow for the dispersion of a large number of catalytically active sites. Secondly, it possesses uniform hexagonal channels, which can be tuned from 5 to $30 \mathrm{~nm}$, and a very narrow pore-size distribution [1]. Therefore, SBA15 allows for rigorous control of the surface geometry at the mesoscale, which is an important ingredient for the design of catalysts [2]. Its large pores permit access to bulky reagents. Furthermore, the thick framework walls (3.1-6.4 nm) of SBA-15 provide high hydrothermal stability that exceeds those of other mesoporous materials e.g. thinner-walled MCM-41 [3]. Although of great potential use for catalytic applications, there have been only few reports on the preparation and/or reactivity behavior of SBA-15 supported catalysts. Only recently, SBA-15 supported vanadia was used for the photo-induced oxidation of methane to formaldehyde (FA) [4] and oxidative dehydrogenation (ODH) of propane [5].

Supported vanadia catalysts possess unique properties for a number of reactions such as the oxidation of sulfur dioxide to sulfur trioxide [6], oxidation of o-xylene to phthalic anhydride $[7,8]$ and selective catalytic reduction of $\mathrm{NO}_{x}[6,9]$. The gas-phase partial oxidation

\footnotetext{
* To whom correspondence should be addressed.
}

of methanol to FA is an important probe reaction, as its product selectivity depends on the surface concentration of redox, basic and acidic sites [6,8,10-12]. Redox sites produce FA, methyl formate (MF) and dimethoxymethane (DMM), whereas acidic and basic sites give rise to dimethyl ether and carbon oxides $\left(\mathrm{CO}_{x}\right)$, respectively. Silica-supported vanadia catalysts are very selective towards FA, but exhibit a rather low activity in comparison to a series of vanadia catalysts supported on other oxides, such as titania $[8,11]$. Recently, the reactivity of vanadium oxide supported on mesoporous silica MCM-48 towards methanol oxidation at $400{ }^{\circ} \mathrm{C}$ was examined and compared to that of (amorphous) silica supported vanadia [13]. Remarkably, the MCM-48 supported catalysts gave higher yields of FA in comparison to the silica samples with the same vanadium loading. With increasing V loading, an increase in conversion and FA yield was observed. However, samples containing a fraction of crystalline vanadium oxide showed a decrease in activity and FA yield as a result of a loss of accessible active sites in the $\mathrm{V}_{2} \mathrm{O}_{5}$ crystal lattice [13]. It is therefore highly desireable to synthesize a robust catalyst material with the maximum density of isolated or polymeric tetracoordinate vanadium sites, which necessitates the use of a high surface area support.

Grafting methods are widely used to prepare catalysts on supporting materials [14-16]. In a previous study, 3aminopropyltrimethoxy-silane (APTMS) has been used as a linker to attach iron and copper species to the surface of MCM-41 [17]. Recently, by using molecular 
designed dispersion (MDD) of $\mathrm{VO}(\mathrm{acac})_{2}$, highly dispersed $\mathrm{VO}_{x}$ species have been grafted on MCM-48 $[13,18] . \mathrm{VO}_{x} /$ SBA-15 materials can be prepared by a grafting/anion exchange method to anchor transition metal oxides to a high surface area support $[19,20]$. This method consists of (1) functionalization of the inner pores of SBA-15 with APTMS, (2) ion-exchanging the precursor (decavanadate) into the pores of the mesoporous matrix and (3) decomposition of the precursor material during calcination yielding a highly dispersed supported transition metal oxide catalyst.

In this contribution, reactivity results for the partial oxidation of methanol to FA over SBA-15 supported vanadium oxide are presented. Raman characterization of the catalyst after reaction is used to elucidate structural changes of the surface vanadium oxide species during methanol oxidation. We focus on well-characterized highly dispersed $\mathrm{VO}_{x}$ catalysts with vanadium loadings of up to $7.2 \mathrm{wt} \% \mathrm{~V}$, for which the maximum experimental dispersion of vanadia was obtained.

\section{Experimental section}

\subsection{Support preparation}

Silica SBA-15 was synthesized according to the literature [1]. The resulting white powder was calcined at $550{ }^{\circ} \mathrm{C}$ for $12 \mathrm{~h}$ to obtain the final product.

\subsection{Catalyst preparation}

Functionalization of SBA-15 was achieved by stirring $2.5 \mathrm{~g} \mathrm{SBA}-15$ in $100 \mathrm{~mL}$ of toluene at $65^{\circ} \mathrm{C}$ as described in [17]. To this suspension, $6.5 \mathrm{~g}$ 3-APTMS was added while stirring. After stirring for $12 \mathrm{~h}$, the contents were filtered and washed with toluene. This dry, white powder was stirred in $150 \mathrm{~mL} 0.3 \mathrm{M} \mathrm{HCl}$ for $12 \mathrm{~h}$. The contents were filtered again, washed with water and dried in air overnight, yielding $4.8 \mathrm{~g}$ of white powder. Elemental analysis indicated a carbon content of $11.33 \%$ and a nitrogen content of $3.55 \%$ for a sample dried in air at $85^{\circ} \mathrm{C}$. SBA-15 supported vanadia was synthesized using functionalized SBA-15 and butylammonium decavanadate as starting material, which was synthesized according to a previous report [21]. As an example, for a $2.3 \mathrm{wt} \% \mathrm{~V}$ catalyst, $73 \mathrm{mg}$ of butylammonium decavanadate were added to a suspension of $1 \mathrm{~g}$ functionalized SBA-15 in $40 \mathrm{~mL}$ water. The contents were stirred for $12 \mathrm{~h}$, filtered, washed with water and dried in air, yielding an orange powder. The powder was calcined at $550{ }^{\circ} \mathrm{C}$ for $12 \mathrm{~h}$.

\subsection{Physical characterization}

The vanadium content of the $\mathrm{VO}_{x} / \mathrm{SBA}-15$ samples was determined at Galbraith Laboratories. Knoxville, TN [19]. Surface areas of the prepared samples were measured by nitrogen adsorption/desorption isotherms using a Quantachrome Autosorb-1 surface area analyzer. The pore volume was determined from the adsorption branch of the $\mathrm{N}_{2}$ isotherm curve at the $P / P_{0}=0.995$ signal point. The pore-size distribution was calculated using the Barrett-Joyner-Halenda (BET) method. Elemental analysis reveals $\mathrm{Cu}, \mathrm{Ni}$ and $\mathrm{Zn}$ in the ppm level of the prepared SBA- 15 .

\subsection{Raman spectroscopy}

The Raman spectrometer (Kaiser Optical) was equipped with a Nd:YAG laser that is frequency doubled to $532 \mathrm{~nm}$. The laser was operated at a power level of $25 \mathrm{~mW}$ measured at the sample using a power meter (Coherent). The spectral resolution of the spectrometer is $5 \mathrm{~cm}^{-1}$. To minimize the effect of laser heating, the samples $(\sim 50 \mathrm{mg})$ were pressed into pellets at $40 \mathrm{MPa}$ and rotated at $20 \mathrm{~Hz}$ within a rotary quartz in situ Raman cell. The in situ Raman cell is heated via tightly wound heating wires and thermally insulated with a ceramic material. It is equipped with a thermocouple probe and inlet and outlet gas connections. Raman spectra under dehydrated conditions were recorded at room temperature after treating the samples in flowing air at $400{ }^{\circ} \mathrm{C}$ for $1 \mathrm{~h}$. Sampling times were typically $5 \mathrm{~min}$.

\subsection{UV-VIS diffuse reflectance spectroscopy}

Diffuse reflectance UV-VIS spectra were measured with a Varian-Cary 4 spectrometer equipped with a Harrick diffuse reflectance attachment. Samples were dehydrated in $20 \% \mathrm{O}_{2} / \mathrm{He}$ at $300{ }^{\circ} \mathrm{C}$ for $1 \mathrm{~h}$ before measuring spectra between 1 and $5 \mathrm{eV}$ at ambient temperature. The Kubelka-Munk function $(F(R \infty))$ was used to convert diffuse reflectance data into absorption spectra using $\mathrm{MgO}$ as a standard.

\subsection{Reactivity experiments}

Two hundred milligram of catalyst was loaded into a Pyrex tubular flow reactor with a $10 \mathrm{~mm}$ inner diameter. A glass frit was permanently positioned in the reactor for reproducible loading and positioning relative to the thermocouple in the reactor. The reactor was placed in a tubular furnace. The temperature was controlled with a feedback controller and continuously monitored using data acquisition software. Each catalyst was pretreated at $500{ }^{\circ} \mathrm{C}$ for $1 \mathrm{~h}$ in a stream of synthetic air $\left(20 \% \mathrm{O}_{2}\right.$, $80 \% \mathrm{He}$ ) prior to each run. Following pretreatment, a $\mathrm{MeOH} / \mathrm{O}_{2} / \mathrm{He}$ gas mixture $(3 / 7 / 90)$ was introduced to the reactor at a total flow rate of $100 \mathrm{~mL} / \mathrm{min}$. Methanol was introduced using a temperature-controlled saturator with $\mathrm{He}$ as the carrier gas. All lines associated with the feed and products were heated to avoid condensation of methanol and the products. The reactant and product mix was analyzed by a gas chromatograph (Agilent 6890) equipped with a capillary column (Alltech, AT aquawax; polyethylene glycol stationary phase) 
connected to a flame ionization detector (FID) and a packed column (Alltech, Haysep DB packing) connected to a thermal conductivity detector (TCD). Oxygenated compounds (methanol, $\mathrm{MeOH}$; methyl formate, MF; dimethoxymethane, DMM; dimethyl ether, DME, and formaldehyde, FA) were detected using the FID, Fixed gases (carbon monoxide, oxygen, carbon dioxide) were detected using the TCD. Complete product analysis run time was approximately $30 \mathrm{~min}$. Three points were taken at each temperature or residence time. Catalytic runs began $30 \mathrm{~min}$ after methanol flow through the catalyst at 300,350 and $400{ }^{\circ} \mathrm{C}$ in increasing order of temperature. At $400{ }^{\circ} \mathrm{C}$, flow rates were varied $(50-200 \mathrm{~mL} / \mathrm{min})$ to obtain the selectivity versus conversion data.

The reported conversion values were calculated based on an appropriate weighted sum of the product concentrations (equation 1)

$$
\mathrm{MeOH} \text { Conversion }=\left(\sum_{i} v_{i} X_{i}\right) * 100,
$$

where $v_{i}$ is the number of carbons from methanol necessary to make product $i$, and $X_{i}$ is the mole fraction of product $i$. The selectivity ( $\%$ ) of product $i$ is reported on the basis of product areas as (the number of moles of methanol converted to product $i$ )/(total number of moles of methanol converted) $\times 100$. The turnover frequency, TOF $\left(\mathrm{s}^{-1}\right)$ is the number of moles of methanol converted to FA per mole of surface vanadium atom per second.

\section{Results and discussion}

\subsection{Synthesis of $V O_{x} / S B A-15$}

The synthesis and characterization of SBA-15 has been discussed previously [1]. The results of the $\mathrm{N}_{2}$ physisorption analysis of SBA-15 and the $\mathrm{VO}_{x} / \mathrm{SBA}-15$ $(0-7.2 \mathrm{wt} \% \mathrm{~V})$ samples are given in table 1 . With increasing vanadia loading, the surface areas, pore radii and pore volumes of the $\mathrm{VO}_{x} / \mathrm{SBA}-15$ shift to lower values (see table 1). However, physisorption data also reveals that in the presence of surface vanadia, the mesoporous channels remain accessible. The pore radius and pore volume decrease significantly with loading, which suggests that the vanadia species are located inside the pores of SBA-15, coating the inner walls of the mesoporous matrix.
The formation of $\mathrm{VO}_{x} / \mathrm{SBA}-15$ can be summarized as follows [19]: (1) SBA-15 is modified by grafting of 3-APTMS and subsequent formation of the corresponding ammonium salt. As has been shown previously for 3-aminopropyltetraethoxysilane (APTS), after hydrolysis both bidentate and tridentate (polymerized) APTS molecules are present. (2) Decavanadate ions $\left(\mathrm{V}_{10} \mathrm{O}_{28}{ }^{6-}\right)$ are incorporated intact into the pores using anion exchange, without any indication for structural changes of the organic framework, as evidenced by Raman spectroscopy. (3) Calcination of the decavanadate precursor yields the chemically bonded vanadia species. During this process, the ammoniumpropyl chains used for functionalization are removed from the pores.

\subsection{Spectroscopic characterization of $V O_{x} / S B A-15$}

UV-VIS spectra of the blank SBA-15 support and the $\mathrm{VO}_{x} / \mathrm{SBA}-15$ samples after calcination are depicted in figure 1 in their dehydrated state. The corresponding Raman spectra are shown as insets. The dehydrated $\mathrm{VO}_{x} / \mathrm{SBA}-15$ samples give rise to absorption bands at 250 and $292 \mathrm{~nm}$, respectively. The position of their maxima agrees well with that of orthovanadate reference compounds such as $\mathrm{Na}_{3} \mathrm{VO}_{4}$ [22] and $\mathrm{Mg}_{3} \mathrm{~V}_{2} \mathrm{O}_{8}$ $[23,24]$. Also, the corresponding Raman spectra are dominated by a band at $1040 \mathrm{~cm}^{-1}$ (see inset), which has been assigned to isolated tetrahedral $\mathrm{VO}_{4}$ with three $\mathrm{V}-\mathrm{O}_{\text {support }}$ bonds and one $\mathrm{V}=\mathrm{O}$ bond in the literature [25-29]. It should be mentioned, that recent studies have challenged the above assignment [30,31]. At a loading of $7.2 \mathrm{wt} \% \mathrm{~V}$, an additional band appears at $362 \mathrm{~nm}$ [32]. The position of this band indicates the presence of polymerized $\mathrm{VO}_{4}$, but its contribution to the total intensity is small. This assignment is supported by comparison with meta-vanadate reference compounds with polymerized $\mathrm{VO}_{4}$ such as $\mathrm{Na}_{3} \mathrm{VO}_{3}$ [33] and $\mathrm{NH}_{4} \mathrm{VO}_{3}$ [34], which show absorption bands at 353 and $363 \mathrm{~nm}$, respectively.

Besides the Raman band at $1040 \mathrm{~cm}^{-1}$, the dehydrated vanadia samples give rise to additional bands at 915 and $1072 \mathrm{~cm}^{-1}$, which can be assigned to $\mathrm{Si}-\mathrm{O}^{-}$and $\mathrm{Si}\left(-\mathrm{O}^{-}\right)_{2}$ functionalities indicating the formation of $\mathrm{V}-$ O-Si $[21,35]$. In contrast to the vanadia samples, the blank SBA-I5 support gives rise to only one Raman band at $987 \mathrm{~cm}^{-1}$, which is characteristic of the $\mathrm{Si}-\mathrm{OH}$ stretching mode of surface hydroxyls [36]. Obviously,

Table 1

BET characteristics of the synthesized SBA-15 supported vanadium oxides compared to the blank SBA-15 support

\begin{tabular}{ccccccc}
\hline & $\mathrm{V}(\mathrm{wt} \%)$ & $\mathrm{V} / \mathrm{nm}^{2}$ & $\mathrm{~V}(\mathrm{mmol} / \mathrm{g})$ & $S_{\mathrm{BET}}\left(\mathrm{m}^{2} / \mathrm{g}\right)$ & $r_{p}(\mathrm{~nm})$ & $\mathrm{V}_{p}(\mathrm{~mL} / \mathrm{g})$ \\
\hline SBA-15 & 0.0 & 0.0 & 0.0 & 826 & 3.58 & 0.77 \\
$\mathrm{VO}_{x} /$ SBA-15 & 2.3 & 0.6 & 0.45 & 445 & 3.26 & 0.46 \\
& 7.2 & 2.3 & 1.4 & 369 & 2.83 & 0.36 \\
\hline
\end{tabular}




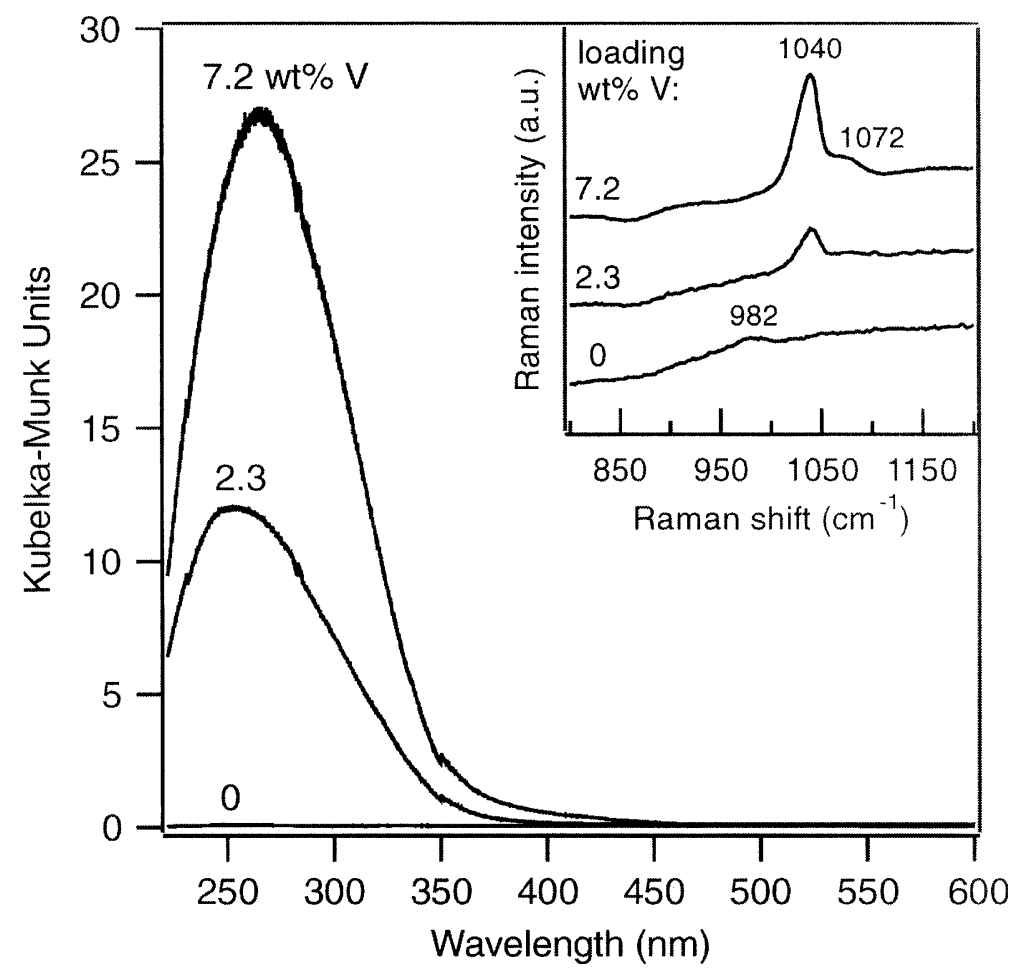

Figure 1. UV-VIS diffuse reflectance spectra of blank SBA-15 and dehydrated SBA-15 supported vanadium oxide catalysts. The inset shows the corresponding Raman spectra.

upon grafting of vanadia, its intensity decreases as a result of the reaction of $\mathrm{Si}-\mathrm{OH}$ with the vanadi a precursor.

\subsection{Reactivity behavior during methanol oxidation}

Table 2 shows the reactivity data for the partial oxidation of methanol to FA over highly dispersed vanadia supported on SBA-15 (2.3 and $7.2 \mathrm{wt} \% \mathrm{~V} /$ SBA-15). TOF and selectivities are presented for 300 and $400{ }^{\circ} \mathrm{C}$. Negligible gas-phase activity was found over the reaction range of interest. No significant conversion of FA was observed below $300{ }^{\circ} \mathrm{C}$ [37]. The results in table 2 clearly show that SBA-15 supported vanadium oxides are very selective towards FA. Selectivities range between $96 \%\left(300{ }^{\circ} \mathrm{C}, 3-8 \%\right.$ methanol conversion) and $88 \%\left(400{ }^{\circ} \mathrm{C}, 64-70 \%\right.$ methanol conversion). The TOF shows no variation with increasing vanadium loading. This result may be expected as the spectroscopic data (figure 1) shows only minor structural changes of the surface vanadium oxide species [32]. The apparent activation energy amounts to $23.6 \mathrm{kcal} / \mathrm{mol}$ as estimated on the basis of TOF values obtained for the $2.3 \mathrm{wt} \% \mathrm{~V} / \mathrm{SBA}-15$ catalyst at low methanol conversions $(<17 \%)$ within $300-350{ }^{\circ} \mathrm{C}$. This value is slightly higher than the $19.6 \pm 2.3 \mathrm{kcal} / \mathrm{mol}$ obtained for silica supported vanadium oxide within 200-240 ${ }^{\circ} \mathrm{C}[11]$. Recently, for silica supported molyb-

Table 2

Reactivity data for methanol oxidation to $\mathrm{FA}$ over $\mathrm{VO}_{x} / \mathrm{SBA}-15$ catalysts as well as SBA- 15 at $300{ }^{\circ} \mathrm{C}\left(3-8 \% \mathrm{MeOH}\right.$ conversion) and $400{ }^{\circ} \mathrm{C}$ $(64-70 \% \mathrm{MeOH} \text { conversion })^{\mathrm{a}}$

\begin{tabular}{|c|c|c|c|c|c|c|}
\hline & $\operatorname{TOF}^{\mathrm{b}}\left(\times 10^{3} \mathrm{~s}^{-1}\right)$ & FA & MF & Selectivity DMM & DME & $\mathrm{CO}_{x}$ \\
\hline \multicolumn{7}{|c|}{$300{ }^{\circ} \mathrm{C}$} \\
\hline SBA-15 & & 65.3 & 2.6 & 0.2 & 0.0 & 31.9 \\
\hline $2.3 \mathrm{wt} \% \mathrm{~V} / \mathrm{SBA}-15$ & 0.7 & 96.3 & 1.2 & 0.5 & 2.0 & 0.0 \\
\hline $7.2 \mathrm{wt} \% \mathrm{~V} / \mathrm{SBA}-15$ & 0.5 & 95.8 & 0.9 & 0.8 & 2.5 & 0.0 \\
\hline \multicolumn{7}{|c|}{$400{ }^{\circ} \mathrm{C}$} \\
\hline SBA-15 & & 17.0 & 0.3 & 0.0 & 0.0 & 82.7 \\
\hline $2.3 \mathrm{wt} \% \mathrm{~V} / \mathrm{SBA}-15$ & 11.2 & 88.1 & 0.1 & 0.0 & 0.2 & 11.6 \\
\hline $7.2 \mathrm{wt} \% \mathrm{~V} / \mathrm{SBA}-15$ & 5.5 & 88.7 & 0.1 & 0.0 & 0.3 & 10.9 \\
\hline
\end{tabular}

${ }^{\mathrm{a}}$ At $350{ }^{\circ} \mathrm{C}$, FA selectivities of $94.0 \%$ (16.1\% MeOH conversion) and $93.2 \%$ (39\% MeOH conversion) were obtained for $2.3 \mathrm{wt} \% \mathrm{~V} / \mathrm{SBA}-15$ and $7.2 \mathrm{wt} \% \mathrm{~V} / \mathrm{SBA}-15$, respectively.

${ }^{\mathrm{b}}$ Apparent TOF values. 
denum oxide a comparable apparent activation energy of $21.3 \mathrm{kcal} / \mathrm{mol}$ was obtained within $200-350{ }^{\circ} \mathrm{C}$, which is consistent with cleavage of the $\mathrm{C}-\mathrm{H}$ bond in the adsorbed methoxy species being the rate-determining step in methanol oxidation [38].

Figure 2 shows the selectivity for FA as a function of methanol conversion for highly dispersed SBA-15 supported vanadium oxide at $400{ }^{\circ} \mathrm{C}$, together with a leastsquare fit to the experimental data The data was obtained by varying the residence time from 0.17 to $0.69 \mathrm{~s}$ while keeping the temperature of the catalyst constant. With increasing conversion the selectivity decreases. However, even at methanol conversions of $87 \%$, high FA selectivities of $83 \%$ are obtained, which result in a FA yield of $72 \%$. Above $400{ }^{\circ} \mathrm{C}$, the fraction of products of unselective oxidation reactions $\left(\mathrm{CO}_{x}\right)$ strongly increases with temperature. For the $7.2 \mathrm{wt} \% \mathrm{~V} /$ SBA-15 catalyst, the CO, fraction increases from $17 \%$ $\left(400{ }^{\circ} \mathrm{C}\right)$ to $30 \%\left(430{ }^{\circ} \mathrm{C}\right)$ and $45 \%\left(460{ }^{\circ} \mathrm{C}\right)$ at $94-99 \%$ methanol conversion.

Besides FA, small amounts of MF, DMM and dimethyl ether (DME) as well as $\mathrm{CO}_{x}$ are formed over $\mathrm{VO}_{x} / \mathrm{SBA}-15$. MF and DMM are produced over redox sites (as is FA), while DME and $\mathrm{CO}_{x}$ form over acidic and basic sites, respectively. The oxidation of methanol yields DME indicating the presence of acidic sites. Interestingly, no DME is observed for the blank SBA-15 support within $300-400{ }^{\circ} \mathrm{C}$. This behavior is in agreement with the results from recent $\mathrm{NH}_{3}$ TPD studies on SBA-15 [5], which have shown no appreciable desorption peaks corresponding to medium acid sites. The formation of significant amounts of FA and MF indicates the presence of redox sites on the bare support.

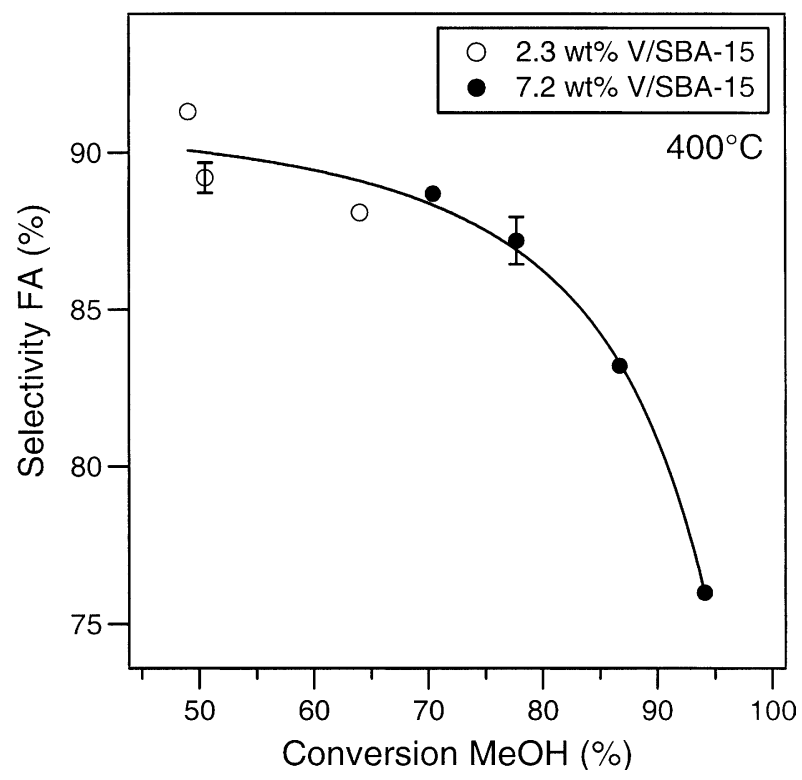

Figure 2. Formaldehyde selectivity as a function of conversion for methanol oxidation to FA over SBA-15 supported vanadia catalysts at $400{ }^{\circ} \mathrm{C}$ together with a fit to the data as well as error bars (standard deviation $\sigma$ ) for selected data points.
Although transition metal contamination found in the SBA-15 may explain this activity (see above), the intrinsic activity of SBA-15 is supported by reactivity experiments on ultrapure SBA-15, which show a significantly higher activity compared to conventional SBA-15 [39]. In comparison, for MCM and conventional $\mathrm{SiO}_{2}$ materials, the formation of DME but no MF was observed [13]. These results indicate significant differences in the properties of conventionally prepared SBA-15 compared to other $\mathrm{SiO}_{2}$ materials, which are currently under study in our laboratory.

Table 3 summarizes the catalytic performance (conversion, selectivity, yield) of highly dispersed vanadia supported on various conventional and mesoporous silica materials. Comparison of the reactivity results over vanadia supported on Kieselgel, MCM-48 and SBA-15 (-0.4 mmol V/g) at $400{ }^{\circ} \mathrm{C}$ demonstrates that a better catalytic performance is obtained on vanadia supported on mesoporous silica. This can be explained by the higher surface area of the mesoporous support materials, which allows for the formation of highly dispersed $\mathrm{VO}_{x}$ species at higher loading of vanadium. Interestingly, even at low vanadium loadings $(<0.4 \mathrm{mmol} \mathrm{V} / \mathrm{g}$ ), vanadia supported on mesoporous silica gives better catalytic results. It has been reported that the maximum experimental dispersion for vanadia supported on MCM-48 and SBA-15 is achieved at a loading of $1.4 \mathrm{mmol} / \mathrm{g}[18,19]$. At this loading, the catalytic performance of $\mathrm{VO}_{x} / \mathrm{SBA}-15$ compares favorably with that of $\mathrm{VO}_{x} / \mathrm{MCM}-48$ [18]. As shown in table 3 and figure 2, slightly higher FA selectivities and yields are obtained for the $\mathrm{VO}_{x} / \mathrm{SBA}-15$ catalysts.

\subsection{Catalyst characterization after methanol oxidation}

Figure 3 shows Raman spectra of a $7.2 \mathrm{wt} \% \mathrm{~V} / \mathrm{SBA}$ 15 catalyst taken at room temperature before (a) and after exposure to the $\mathrm{MeOH} / \mathrm{O}_{2} / \mathrm{He}$ gas mixture at temperatures, at which no reaction $\left(200-240{ }^{\circ} \mathrm{C}\right)(\mathrm{b})$ and extensive reaction $\left(400-460{ }^{\circ} \mathrm{C}\right)(\mathrm{d})$ occurs. The corresponding spectra after air treatment at $500{ }^{\circ} \mathrm{C}$ for $1 \mathrm{~h}$ are shown as spectra c and e [41]. Spectrum a is characterized by bands at 518,706 , and $1023 \mathrm{~cm}^{-1}$, which can be assigned to hydrated vanadium oxide forming a $\mathrm{V}_{2} \mathrm{O}_{5} \cdot n \mathrm{H}_{2} \mathrm{O}$ gel-like structure [26,27]. Exposure to the $\mathrm{MeOH} / \mathrm{O}_{2} / \mathrm{He}$ gas mixture at temperatures, at which no reaction was observed, leads to dramatic changes in the Raman spectrum (b). Bands appear at 484, 927, 1032, $2832,2863,2939$, and $2962 \mathrm{~cm}^{-1}$. The bands in the highfrequency region result from adsorbed methanol forming a methoxy species. They can be attributed to $\mathrm{C}-\mathrm{H}$ symmetric stretching vibrations of methoxy adsorbed on silica SBA-15 $\left(2863,2962 \mathrm{~cm}^{-1}\right)$ and vanadia (2832, $2939 \mathrm{~cm}^{-1}$ ) as shown previously for vanadia supported on Cab-O-Sil [42]. The Raman band at $1032 \mathrm{~cm}^{-1}$ is assigned to the stretching vibration of $\mathrm{V}=\mathrm{O}$ double bonds in hydrated vanadium oxide forming a $\mathrm{V}_{2} \mathrm{O}_{5}$. 
Table 3

Methanol oxidation to FA over highly dispersed vanadia supported on silica

\begin{tabular}{|c|c|c|c|c|c|c|c|c|}
\hline Support & $\mathrm{V}(\mathrm{mmol} / \mathrm{g})$ & $\mathrm{V} / \mathrm{nm}^{2}$ & $T\left({ }^{\circ} \mathrm{C}\right)$ & $\mathrm{C}_{3} \mathrm{H}_{8} / \mathrm{O}_{2} / \mathrm{He}(\mathrm{mL} / \mathrm{min})$ & $X(\mathrm{MeOH}) \%$ & $S(\mathrm{FA})(\%)$ & $Y(\mathrm{FA})(\%)$ & References \\
\hline \multirow[t]{2}{*}{ Cab-O-Sil } & 0.11 & 0.22 & 230 & $6 / 13 / 81$ & $<20$ & 72 & & {$[6,11]$} \\
\hline & 0.33 & 0.66 & 230 & & $<20$ & 45 & & \\
\hline \multirow{2}{*}{$\mathrm{SiO}_{2}{ }^{\mathrm{a}}$} & 0.32 & $0.43-0.47^{\mathrm{b}}$ & 310 & $24 / 58 / 216^{c}$ & & 90 & & {$[40]$} \\
\hline & & & 345 & & & 84 & & \\
\hline \multirow[t]{2}{*}{ SBA-15 } & 0.45 & 0.6 & 300 & $3 / 7 / 90$ & 3.2 & 96.3 & 3.1 & This work \\
\hline & & & 350 & & 16.1 & 94.0 & 15.1 & \\
\hline \multirow[t]{2}{*}{ MCM-48 } & 1.4 & 0.75 & 300 & $3.2 / 6.4 / 70.4$ & 24 & 60 & 14 & [18] \\
\hline & 1.4 & & 350 & & 38 & 85 & 32 & \\
\hline \multirow[t]{2}{*}{ SBA-15 } & 1.4 & 2.3 & 300 & $3 / 7 / 90$ & 7.8 & 95.8 & 7.5 & This work \\
\hline & & & 350 & & 39.0 & 93.3 & 36.4 & \\
\hline \multirow[t]{2}{*}{ Kieselgel 60} & 0.2 & 0.4 & 400 & $3.2 / 6.4 / 70.4$ & 21.0 & 79.3 & 16.6 & [13] \\
\hline & 0.4 & 0.94 & & & 45.0 & 88.0 & 39.6 & \\
\hline \multirow[t]{4}{*}{ MCM-48 } & 0.2 & 0.1 & 400 & $3.2 / 6.4 / 70.4$ & 31.0 & 98.1 & 30.4 & [13] \\
\hline & 0.4 & 0.2 & & & 60.9 & 94.7 & 57.7 & \\
\hline & 0.7 & 0.31 & & & 75.0 & 92.8 & 69.6 & \\
\hline & 1.4 & 0.75 & 400 & & 55 & 85 & 47 & [18] \\
\hline \multirow[t]{2}{*}{ SBA-15 } & 0.45 & 0.6 & 400 & $3 / 7 / 90$ & 49 & 91.3 & 44.7 & This work \\
\hline & 1.4 & 2.3 & 400 & & 86.7 & 83.2 & 72.1 & \\
\hline
\end{tabular}

${ }^{a}$ Silica was prepared by hydrolysis of ethyl orthosilicate [40]. ${ }^{b}$ Value for singly impregnated catalyst is expected within given range. Boundary values are based on the surface areas obtained for a doubly impregnated catalyst and bare $\mathrm{SiO}_{2}$, respectively [40]. ${ }^{\mathrm{c}}$ In this study, $\mathrm{N}_{2}$ was used instead of $\mathrm{He}[40]$.

$n \mathrm{H}_{2} \mathrm{O}$ gel-like structure. The blue-shift of the band at $1023 \mathrm{~cm}^{-1}$ can be explained by the variation of the water content $n$ in the gel [27]. In the same study it has been shown, that the variation of the water content in the gel can also lead to the presence of an additional band at $\sim 915 \mathrm{~cm}^{-1}$, which has been attributed to the stretching of $\mathrm{V}=\mathrm{O}$ double bond coordinated with water. Also, in an earlier study, the appearance of a Raman band at $\sim 920 \mathrm{~cm}^{-1}$ upon exposure to water had been reported [26]. On the basis of these results, the broad band around $927 \mathrm{~cm}^{-1}$ is assigned to the stretch vibration of $\mathrm{V}=\mathrm{O}$ double bonds coordinated with water. Obviously, the presence of methanol in the gel cannot be ruled out. However, the fact that similar spectra (spectra $b$ and $d$ ) are obtained despite the exposure to the $\mathrm{MeOH} / \mathrm{O}_{2} / \mathrm{He}$ mixture under very different conditions, supports the above interpretation. The shoulder at $\sim 1070 \mathrm{~cm}^{-1}$ can be associated with the $\mathrm{C}-\mathrm{O}$ stretching of a V-methoxy species [27]. This assignment is supported by the fact that the shoulder as well as the other methoxy related
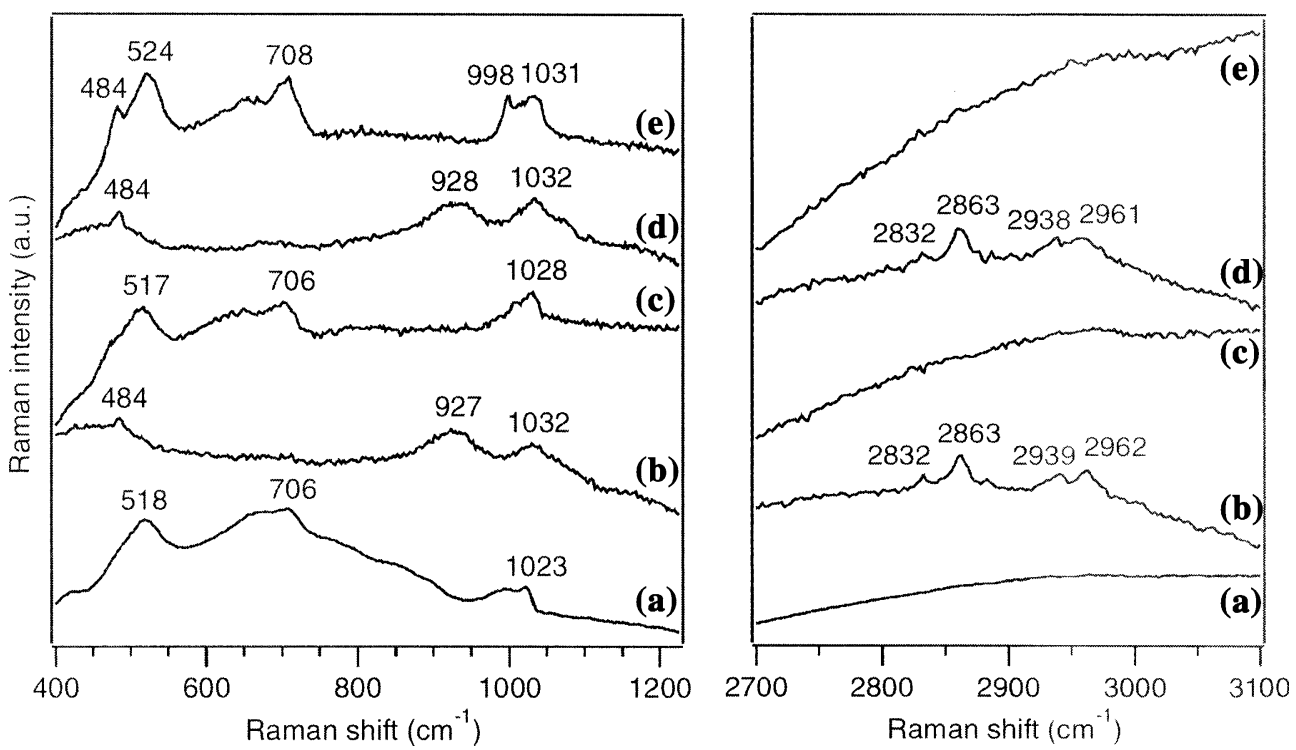

Figure 3. Raman spectra of $7.2 \mathrm{wt} \% \mathrm{~V} / \mathrm{SBA}-15$ (a) before methanol oxidation (b) after exposure to the $\mathrm{MeOH} / \mathrm{O}_{2} / \mathrm{He}$ gas mixture within $200-$ $240{ }^{\circ} \mathrm{C}$ and (c) subsequent treatment in air at $500{ }^{\circ} \mathrm{C}$ for $1 \mathrm{~h}(\mathrm{~d})$ after methanol oxidation within $400-460{ }^{\circ} \mathrm{C}$ and (e) subsequent treatment in air at $500{ }^{\circ} \mathrm{C}$ for $1 \mathrm{~h}$. All spectra were taken at room temperature under ambient conditions. They are offset for clarity. 
bands disappear upon heating in oxygen at $500{ }^{\circ} \mathrm{C}$ (see spectrum c). Finally, the band at $484 \mathrm{~cm}^{-1}$ is indicative of the presence of a small amount of crystalline $\mathrm{V}_{2} \mathrm{O}_{5}$ as discussed in more detail below. After treating the catalyst in air at $500{ }^{\circ} \mathrm{C}$ for $1 \mathrm{~h}$, spectrum $\mathrm{c}$ was recorded. It shows similarity with spectrum a, recorded before reaction, and is characterized by Raman bands at 517 , 706 , and $1028 \mathrm{~cm}^{-1}$. No methoxy-related bands were observed. As discussed above, the spectrum resembles that of a $\mathrm{V}_{2} \mathrm{O}_{5} \cdot n \mathrm{H}_{2} \mathrm{O}$ gel. After exposure of $7.2 \mathrm{wt} \% \mathrm{~V} /$ SBA-15 to the $\mathrm{MeOH} / \mathrm{O}_{2} / \mathrm{He}$ gas mixture under reaction conditions, spectrum d is obtained. It strongly resembles spectrum $b$ and demonstrates that adsorbed methoxy is present on the catalyst surface after reaction. Spectrum e is recorded after treatment of this sample in air at $500{ }^{\circ} \mathrm{C}$. Interestingly, new bands have appeared at 484 and $998 \mathrm{~cm}^{-1}$ in comparison to spectrum $\mathrm{c}$, besides the bands at 524, 708, and $1031 \mathrm{~cm}^{-1}$. The Raman bands at 484 and $998 \mathrm{~cm}^{-1}$ correspond to crystalline $\mathrm{V}_{2} \mathrm{O}_{5}$ [26,27]. These Raman results demonstrate that highly dispersed vanadia partly agglomerates into vanadia crystallites during methanol oxidation at high conversion and confirm very recent findings from TPD experiments [43].

\section{Conclusions}

In summary, highly dispersed vanadium oxide supported on mesoporous silica SBA-15 was prepared, characterized and its reactivity studied for the partial oxidation of methanol to FA. The SBA-15 supported vanadium oxide species are highly selective for the production of FA between 300 and $400{ }^{\circ} \mathrm{C}$. Selectivities range between $96 \%$ at low conversion and temperature and $83 \%$ at $400{ }^{\circ} \mathrm{C}$ and $87 \%$ methanol conversion. We report the highest FA yield $(72 \%)$ in the methanol oxidation over silica supported vanadium oxides. It is obtained for the $\mathrm{VO}_{x} \mathrm{SBA}-15$ catalyst with the highest dispersion $(7.2 \mathrm{wt} \% \mathrm{~V})$ at $400{ }^{\circ} \mathrm{C}$. Raman characterization of the catalyst after reaction at high conversion indicates that dispersed vanadia partly agglomerates into vanadia crystallites during methanol oxidation.

\section{Acknowledgments}

The authors thank Jason Bronkema and Richard Brutchey for helpful discussions. C. H. thanks the MaxPlanck Society and the Deutsche Forschungsgemeinschaft for providing fellowships.

\section{References}

[1] D.Y. Zhao, J.L. Feng, Q.S. Huo, N. Melosh, G.H. Fredrickson, B.F. Chmelka and G.D. Stucky, Science 279 (1998) 548.
[2] D. Trong On, D. Desplantier-Giscard, C. Danumah and S. Kaliaguine, Appl. Cat. A 222 (2001) 299.

[3] K. Cassiers, T. Linssen, M. Matthieu, M. Benjelloun, K. Schrijnemakers, P. Van der Poort, P. Cool and E.F. Vansant, Chem. Mater. 14 (2002) 2317.

[4] H.H. Lopez and A. Martinez, Catal. Lett. 83 (2002) 37.

[5] (a) Y.-M. Liu, Y. Cao, K.-K. Zhu, S.-R. Yan, W.-L. Dai, H.-Y. and He, K.-N. Fan, Chem. Commun. (2002) 2832. (b) Y.-M. Liu, Y. Cao, S.-R. Yan, W.-L. Dai and K.-N. Fan, Catal. Lett. 88 (2003) 61. (c) Y.-M. Liu, Y. Cao, N. Li, W.-L. Feng, W.-L. Dai, S.-R. Yan, H.-Y. He and K.-N. Fan, J. Catal. 224 (2005) 417.

[6] G. Deo, I.E. Wachs and J. Haber, Crit. Rev. Surf. Chem. 4 (1994) 141.

[7] C.R. Dias, M.F. Portela and G.C. Bond, J. Catal. 157 (1995) 344.

[8] G.C. Bond and S.F. Tahir, Appl. Catal. 71 (1991) 1.

[9] E.T.V. Vogt, A. Boot, A.J. van Dillen, J.W. Geus, F.J.J.G. Janssen and F.M.G. van der Kerkhof, J. Catal. 114 (1988) 313.

[10] M. Baltes, P. Van der Voort, O. Collart and E.F. Vansant, J. Porous Mater. 5 (1998) 357.

[11] G. Deo and I.E. Wachs, J. Catal. 146 (1994) 323.

[12] P. Van der Voort, M. Baltes, M.G. White and B.F. Vansant, Interf. Sci. 5 (1997) 209.

[13] M. Baltes, K. Cassiers, P. Van der Voort, B.M. Weckhuysen, R.A. Schoonheydt and E.F. Vansant, J. Catal. 197 (2001) 160.

[14] C. Coperet, M. Chabanas, R.P. Saint-Arroman and J.-M. Basset, Angew. Chem. 42 (2003) 15

[15] K.L. Fudjala and T.D. Tilley, J. Catal. 216 (2003) 265 and references therein.

[16] K. Zhu, Z. Ma, Y. Zou and W. Zhou, T. Chen and H. He, Chem. Commun. (2001) 2552.

[17] W.A. Carvalho, M. Wallau and U. Schuchardt, J. Mol. Catal. A 144 (1999) 91.

[18] P. Van der Voort, M. Baltes and E.F. Vansant, Catal. Today 68 (2001) 119.

[19] C. Hess, J.D. Hoefelmeyer and T.D. Tilley, J. Phys. Chem. B 108 (2004) 9703.

[20] K. Zhu, B. Yue, S.-H. Xie, S.-Y. Zhang, B. Zhang, S.-L. Jin and H.-Y. He, Chin. J. Chem. 22 (2004) 33.

[21] P. Roman, A. Aranzabe, A. Luque and J.M. Gutierrez-Zorilla, Mat. Res. Bull. 26 (1991) 731.

[22] M. Nabavi, F. Taulelle, C. Sanchez and M. Verdaguer, J. Phys. Chem. Solids 51 (1990) 1375.

[23] (a) D.S.H. Sam, V. Soenen and J.C. Volta, J. Catal. 123 (1990) 417. (b) G. Busca, G. Ricchiardi, D.S.H. Sam and J.C. Volta, J. Chem. Soc. Faraday Trans. 90 (1994) 1161.

[24] N. Krishnamachari and C. Calvo, Can. J. Chem. 49 (1971) 1629.

[25] (a) M. Schraml-Marth, A. Wokaun, M. Pohl and H.L. Krauss, J. Chem. Soc. Faraday Trans. 87 (1991) 2635. (b) U. Scharf, M. Schraml-Marth, A. Wokaun and A. Baiker, J. Chem. Soc. Faraday Trans. 87 (1991) 3299.

[26] S. Xie, E. Iglesia and A.T. Bell, Langmuir 16 (2000) 7162.

[27] X. Gao, S.R. Bare, B. Weckhuysen and I.E. Wachs, J. Phys. Chem. B 102 (1998) 10842.

[28] N. Das, H. Eckert, H. Hu, I.E. Wachs, J.F. Walzer and F.J. Feher, J. Phys. Chem. 97 (1993) 8240.

[29] G.T. Went, S.T. Oyama and A.T. Bell, J. Phys. Chem. 94 (1990) 4240.

[30] N. Magg, B. Immaraporn, J.B. Giorgi, T. Schroeder, M. Bäumer, J. Döbler, Z. Wu, E. Kondratenko, M. Cherian, M. Baerns, P.C. Stair, J. Sauer and H.-J. Freund, J. Catal. 226 (2004) 88.

[31] O.L.J. Gijzeman, J.N.J. van Lingen, J.H. van Lenthe, S.J. Tinnemanns, D.E. Keller and B. Weckhuysen, Chem. Phys. Lett. 397 (2004) 277.

[32] The UV-VIS spectra shown in figure 1 have been deconvoluted. As a result, the spectrum of a sample with vanadium loading of $7.2 \mathrm{wt} \%$ can be described by three bands with absorption maxima at 250, 292 and $362 \mathrm{~nm}$, respectively, A more detailed description is given elsewhere [19]. 
[33] F. Marumo, M. Isobe, S. Iwai and Y. Kondo, Acta Crystallogr. B 30 (1974) 1628.

[34] H.T. Evans, Krystallogr Z. 114 (1960) 257.

[35] P. McMillan, Am. Mineral. 69 (1986) 622.

[36] (a) D.R. Tallant, B.C. Bunker, C.J. Brinker and CA. Balfe, Mater. Res. Soc. Symp. Proc. 73 (1986) 261. (b) R.H. Stolen and G.E. Walrafen, J. Chem. Phys. 64 (1976) 2623. (c) B.C. Brinker, D.R. Tallant, E.P. Roth and C.S. Ashley, Mater. Res. Soc. Symp. Proc. 61 (1986) 387.

[37] Vanadia was deposited at the colder parts of the reactor during catalytic runs at lower temperatures. This is probably due to methanol-mediated volatilization of surface vanadium oxide. A similar behavior has been reported previously [11].

[38] M. Seman, J.N. Kondo, K. Domen, R. Radhakrishnan and S.T. Oyama, J. Phys. Chem. B 106 (2002) 12965.
[39] Ultrapure SBA-15 was synthesized according to the literature [1], but the reagents used were $99.999 \%$ TEOS, $20 \%$ doubly distilled $\mathrm{HCl}$ and ultrapure $\mathrm{H}_{2} \mathrm{O}$.

[40] J. Kijenski, A. Baiker, M. Glinski, P. Dollenmeier and A. Wokaun, J. Catal. 101 (1986) 1.

[41] Spectra b (c) and d (e) were obtained after methanol oxidation within $200-240{ }^{\circ} \mathrm{C}\left(400-460{ }^{\circ} \mathrm{C}\right)$ for $\sim 14 \mathrm{~h}(\sim 10 \mathrm{~h})$. Starting at $200{ }^{\circ} \mathrm{C}\left(400{ }^{\circ} \mathrm{C}\right)$, the temperature was kept constant for $200 \mathrm{~min}$ and subsequently increased by $30^{\circ} \mathrm{C}\left(30^{\circ} \mathrm{C}\right)$. It was kept constant for $200 \mathrm{~min}$ and then increased by $10{ }^{\circ} \mathrm{C}\left(30^{\circ} \mathrm{C}\right)$. After the final temperature had been reached, it was kept constant for the residual duration of the experiment.

[42] J.-M. Jehng, H. Hu, X. Gao and I.E. Wachs, Catal. Today 28 (1996) 335.

[43] T. Feng and J.M. Vohs, J. Phys. Chem. B 109 (2005) 2120. 